\title{
Reading for long winter evenings
}

\section{Compiled by Helen Nield}

If you have not tried an ebook please email library@bda.org or call 02075634545 for access details. Members can read these books online at any time or download most titles for up to a week before having to download them again. Visit www.bda.org/ebooks to find all of these books and more. The library can now loan books again so contact us if you would like to borrow these instead.

\section{MISCH'S CONTEMPORARY IMPLANT DENTISTRY (4TH ED) \\ Randolph Resnik (Editor) \\ 2020; Elsevier; 1,264 pp; ebook \\ ISBN: 9780323391559}

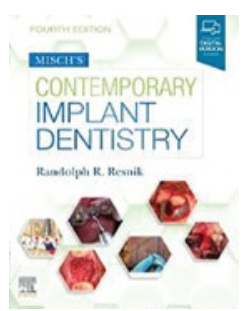

'The goal of modern dentistry is to restore the patient to normal contour, function, comfort, aesthetics, speech, and health by removing a disease process from a tooth or replacing teeth with a prosthesis. What makes implant dentistry unique is the ability to achieve this goal, regardless of the atrophy, disease, or injury of the

stomatognathic disease.'

This title was the winner of the library's dental implant section in a survey to find the most influential dental book since 1920 and so is obviously highly prized. The new fourth edition comes 12 years since the previous one and three years after the death of its first editor, Carl Misch. Dr Resnik who takes over the main editorial duties was a close friend of the latter. A lot has changed since the third edition and the title now consists of eight sections with 42 chapters all of which have been updated - around 20 of the chapters are completely new including one on peri-implantitis and perimucositis and there is an appendix containing treatment planning options. The eight sections are: scientific basis; biomechanical properties of dental implants; fundamental science; treatment planning principles; edentulous site treatment planning; implant surgery; soft and hard tissue rehabilitation; and dental implant maintenance. As Dr Kenneth Judy writes in his foreword to this nearly 1,300-page textbook, '[This] is a classic guide for the student and the young practitioner and a valuable reference for wellexperienced clinicians.' https://tinyurl.com/ebookimplants

\section{PRF APPLICATIONS IN ENDODONTICS}

Mohammed Sabeti, Edward S. Lee and Mahmoud Torabinejad (Editors) 2020; Quintessence; 96 pp; ebook

\section{ISBN: 9780867158274}

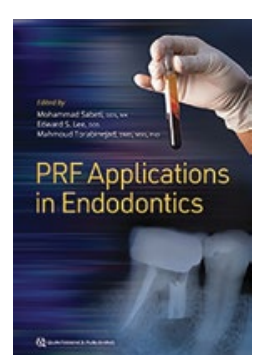

'PRF has many potential applications in endodontics. It can be used in surgical endodontics and adjunctive surgical procedures such as root amputation and hemisection. In addition, it can be used for root perforation repair, vital pulp therapy, and regenerative endodontics. Furthermore, it can be used as a bone graft binder during socket preservation to create "sticky bone" for the

closure of surgical sites.'

Platelet-rich fibrin, already frequently used in bone grafting and augmentation procedures, can also be used in conjunction with a variety of endodontic procedures both surgical and non-surgical. This book is the first to explore the idea of using PRF and cord blood stem cells in endodontics. It begins by providing some background on various cell types found in regenerative medicine then looks more specifically at PRF and its history before moving on to its application in endodontics. Each chapter begins with a series of learning objectives and the chapter on 'PRF in endodontic surgery' contains three case studies covering root-end resection and root resection. The book not only looks at using PRF as part of a 'bone grafting material complex' including 'bone grafting particles and autologous PRF' but also as an alternative to bone grafting and other biomaterials including in cases of accidental tooth loss and replantation. It is aimed at both beginners and more experienced dentists wishing to explore this new field. https://tinyurl.com/ ebooks-endo

\section{OXFORD HANDBOOK OF CLINICAL DENTISTRY (7TH EDITION)}

Bethany Rushworth and Anastasios Kanatas (Editors)

2020; Oxford University Press; 864 pp; ebook

ISBN: 9780198832171

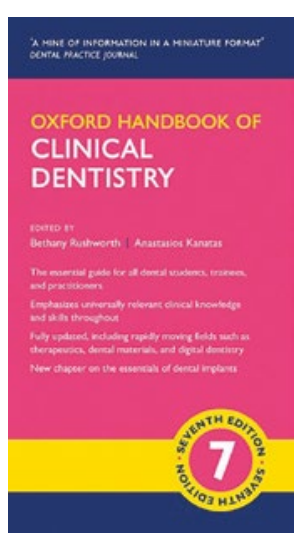

'In the previous edition's preface, this handbook was described as a mature adult refusing to leave home. However, as it rapidly approaches its 30th birthday the time has now come for this invaluable reference tool to enter a new chapter in its life and move forward, following a substantial update and revision under new guardianship.'

Editing rights over this well-known text have been passed on by David and Laura Mitchell to two new editors based in Leeds, Bethany Rushworth and Anastasios Kanatas. The latest edition has been augmented by the addition of new images, tables, resources and links. It has been substantially revised with the addition of a completely new chapter on dental implants as well as information on the latest periodontal classification scheme. It also covers up-to-date management advice for patients who are being prescribed anticoagulants. All drug information is in line with the British National Formulary. In addition, the book contains new information related to medical emergencies and the chapter on practice management has been revised and expanded. The latter now also includes an explanation of the new enhanced CPD guidance. https://tinyurl.com/

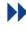
ebooks-oxford 
FUNCTIONAL AESTHETIC DENTISTRY - HOW TO ACHIEVE PREDICTABLE AESTHETIC RESULTS USING PRINCIPLES OF A 14 STABLE OCCLUSION

Neeraj Khanna

2020; Springer; 252 pp; ebook

ISBN: 9783030391140

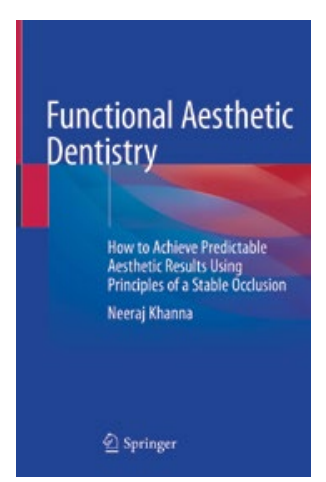

'This book is not meant to be a book of before and after photos, but one that explains the principles of occlusion and how this philosophy can be applied to patients from all walks of life. This philosophy does not discriminate, nor does it assume anything.'

Dr Khanna experienced an epiphany whilst attending a class given by $\mathrm{Dr}$ Peter Dawson which led him firstly to strive to become what Dawson called a 'physician of the masticatory system' and secondly to wish to 'help as many dentists as possible to understand this process of complete dentistry.' This book is the result.

Each chapter begins with a quotation which has meaning to the author and his life although not directly relevant to the text of the chapters themselves. The book consists of ten chapters covering: functional aesthetics; functional occlusion: understanding and thinking; the envelope of function: understanding and importance; the complete examination: the 12 steps needed to perform a complete exam; diagnostic records: what to take and why; incisal edge position: its importance to aesthetics and function; phonetics: how to design with phonetics in mind; diagnosis and treatment planning; communication with your patients/specialists/technicians; preparation, planning and quality control. Sadly, it does not contain an index but it is written in a very easy to read style. https://tinyurl.com/ ebooks-occlusion

\section{Janet Goodwin to be honoured with new FGDP award}

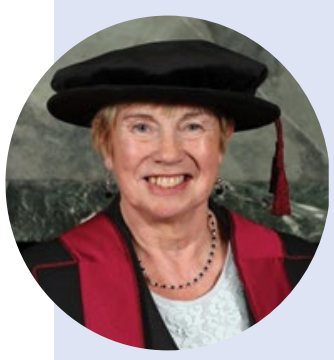

The Faculty of General Dental Practice (UK) (FGDP $[\mathrm{UK}]$ ) is honouring the legacy of the late Janet Goodwin FFGDP(UK)(Hon.) with an award to recognise the achievements of dental care professionals (DCPs).

Over a career spanning almost 50 years, Janet was a staunch advocate for the advancement and recognition of DCPs.

An Affiliate Member of FGDP, she served the Faculty as a representative for the interests of the wider dental team, chairing its DCP Committee, contributing to the development of standards and sitting on the National Faculty Board, and in 2019 she was awarded Honorary Fellowship.

The new Janet Goodwin Award will recognise leadership, standards of professionalism and patient care, commitment to life-long learning, service to the profession and advocacy for the whole-team approach to general dental care.

Open to all GDC-registered DCPs, the inaugural award will be made as part of the FGDP(UK) Annual Awards 2021, and the winner will also receive Affiliate Membership of the Faculty, and its associated benefits, for 2021-22. Nominations are open until 23:59 on Monday 1 March 2021.

Commenting on the new award, FGDP(UK) Dean Ian Mills said: 'Janet was a ground-breaking and influential figure in dentistry, and her passing was mourned throughout the dental profession. She was a fantastic ambassador for our profession, a passionate advocate for the role of the dental team, and a strong supporter of the Faculty. I am therefore delighted that we have been able to commemorate her contribution to dentistry by introducing an annual FGDP(UK) Annual Award in her memory'.

Further details are available at https://www.fgdp.org.uk/news/ fgdpuk-annual-awards-2021.

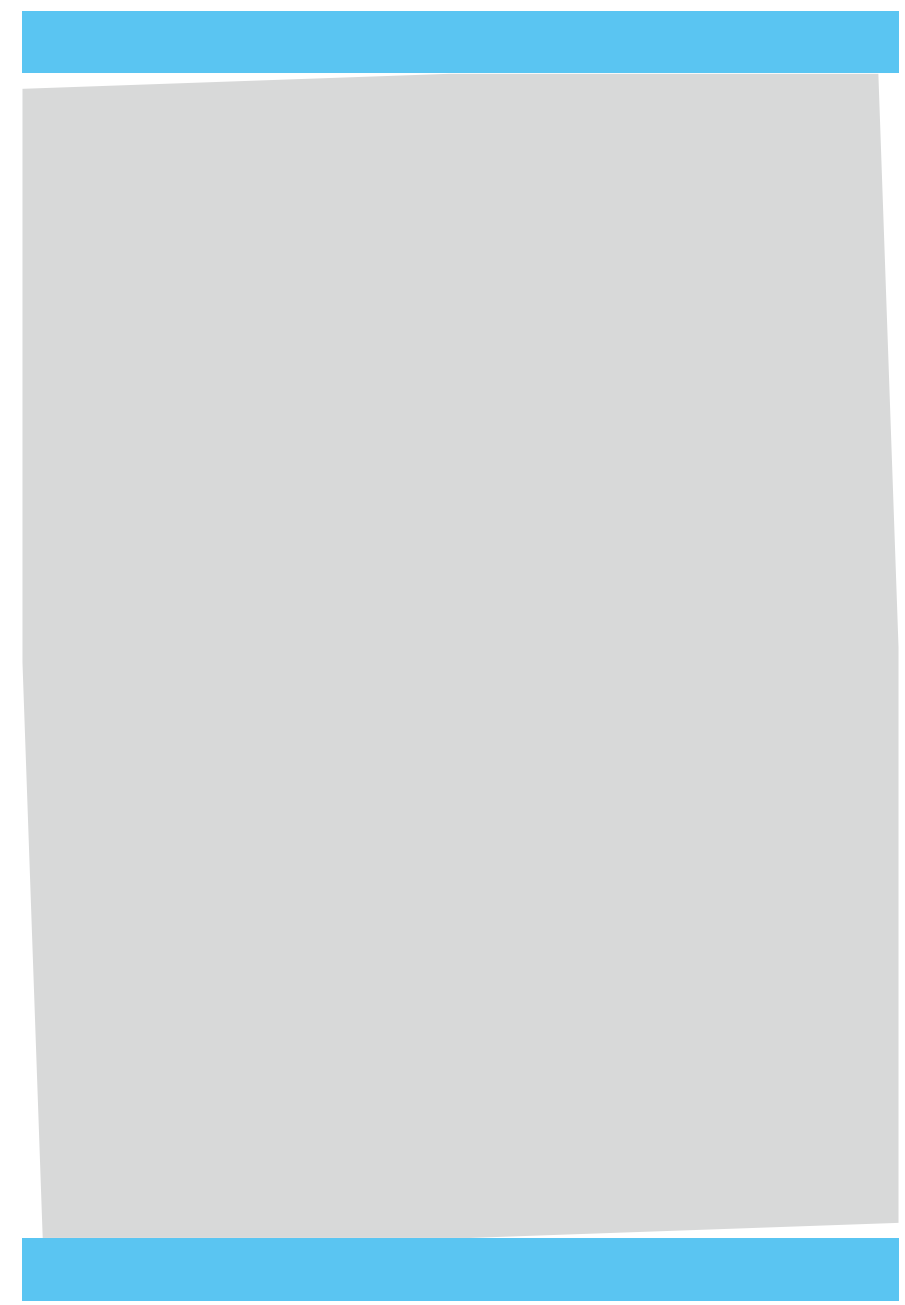

